\title{
A new direction for EJOST!
}

\author{
Pierre Kehr
}

Received: 10 September 2014/ Accepted: 15 September 2014/Published online: 21 September 2014

(C) Springer-Verlag France 2014

It is with great pleasure that we announce the promotion of Dr. Cyril Mauffrey as Editor in Chief of EJOST. This decision rewards the huge efforts and success of our recent indexation into Medline/PubMed. In addition, it gives a clear signal to our readers, authors and editorial board that we are aiming to strengthen our presence in the North American Market. From his position at Denver Health Medical Center and University of Colorado, his leadership of the research division and his professional contacts throughout several continents, Cyril will develop and strengthen the presence and importance of EJOST in the USA.

This promotion will be announced by the following presentation on the first page of the print version and the electronic version of each issue of EJOST:

\section{EDITORS IN CHIEF}

\section{P. Kehr, Strasbourg, France \\ C. Mauffrey, Denver Health Medical Centre, Denver, CO, USA}

\section{DEPUTY EDITORS}

Unchanged alphabetical order but by removing the name of C. Mauffrey

We would like to supplement the current headings "General Review, Original Article, Technical Note, Expert Opinion" with a "master" heading indicative of the specialty of the manuscript: TRAUMA, SPINE, SHOULDER, ELBOW, WRIST, HAND, HIP, KNEE, ANKLE, PAEDIATRICS, SPORT SURGERY, BIOMATERIALS, BIOMECHANICS,
EPIDEMIOLOGY, GENERAL ORTHOPAEDICS, so that the readers can locate the articles easily. Example:

\section{PAEDIATRICS - HIP}

\section{ORIGINAL ARTICLE}

We are aiming to create a new category of article under "Instructional Review." Cyril will encourage senior registrars/chief residents/colleagues to write such articles. We would of course support our Deputy Editors to do the same.

An Editorial will be published several times a year and will make it possible to cover current events, challenges, aspects of research methodology or others. Cyril will make a start, but each Deputy Editor will be able to do the same. These Editorials will have to be injected into EM, like any other article, but their authors will be exempt to name two reviewers; they will be systematically subjected to Cyril and I for validation and then to me for sending with the production after incorporation in a closed issue. The adequate mention of the "Conflict of Interest Disclosure Form" will have to be added at the end of the Editorial.

A Facebook page for EJOST is currently being created.

We hope that you find these news of interest and see the potential of our newly defined targets.

Best regards

Pierre Kehr

E-i-C of EJOST

Conflict of interest None.

P. Kehr $(\bowtie)$

AREDEJOST, Strasbourg, France

e-mail: kehrpier@aol.com 